\title{
Explaining the undulating outcomes of perineal rectosigmoidectomy (Altemeier Procedure) for rectal prolapse over the last century: technique matters!
}

\author{
W. C. Cirocco
}

Received: 2 June 2014 / Accepted: 2 June 2014/Published online: 1 August 2014

(C) Springer-Verlag Italia Srl 2014

Perineal rectosigmoidectomy (PR) as definitive treatment for chronic rectal prolapse has a long history going back to a single case in 1882 (Auffret, France [1]) and the first published series in 1889 (Mikulicz, Germany [2]). Miles at St. Mark's Hospital of London popularized the procedure and reported excellent results with a $3 \%$ recurrence rate in 1933 [3]. However, Hughes [4] and Porter [5] at the same institution were not able to reproduce these results in the decades that followed (1940s-1970s) and recurrence rates of rectal prolapse rose dramatically to $50-60 \%$ as PR fell out of favor and abdominal operations came into vogue.

In the past decade, excellent outcomes reported in many countries (Japan, Brazil, Germany, Italy and the USA) spanning several continents have forced a re-evaluation and resurgence of PR as a viable treatment option, especially for the typical patient population of elderly women [6-9]. Given the recent low rates of recurrence following PR of the past few decades, some centers have even suggested PR for all patients suffering from rectal prolapse, regardless of age $[6,9]$.

Ram et al. [10] present the results of their version of PR using a semicircular stapling device which they refer to as perineal stapled prolapse resection (PSPR), originally described by Scherer et al. [11]. Ram et al. report a short operating time (25-45 $\mathrm{min}$ ) and hospital length of stay (3-5 days); however, they note a very high rate of recurrence $(29 \%)$ which occurred in an alarmingly brief period of time (1, 2, 4 and 6 months into the postoperative period). All of these patients subsequently had their recurrent

W. C. Cirocco $(\varangle)$

Division of Colon \& Rectal Surgery, Department of Surgery, The Ohio State University College of Medicine, Columbus, $\mathrm{OH}$, USA

e-mail: william.cirocco@yahoo.com rectal prolapse corrected by an Altemeier Procedure which combines PR with narrowing of the often stretched and gaping levator hiatus (from the chronic prolapsing rectum) using interrupted absorbable sutures (levatorplasty).

In a retrospective review of my own series of 103 patients who underwent an Altemeier Procedure over the decade of the 2000s (zero recurrence over a mean followup period of 43 months), 12 of these patients presented with recurrent rectal prolapse following various abdominal and perineal operations including four patients who previously had an Altemeier Procedure performed elsewhere. I obtained the operative reports of two of these four patients. These two operations had been performed by colorectal surgeons trained at the same prestigious US-based colorectal surgery residency training program, and they both had $>20$ years of clinical experience. I discovered from the reports dictated by their general surgery residents that the "(pouch) of Douglas was entered at one point, and this was (immediately) closed with 2-0 vicryl suture" in one case, and in the other case, "the peritoneum was exposed and carefully pushed back cephalad using spongesticks. The peritoneum was not entered." These details of these failed operations confirmed that failure to properly perform the Altemeier Procedure was the reason for recurrence of the rectal prolapse, not the operation itself. The peritoneal cavity should be breached early in the dissection in order to fully mobilize the rectum allowing for a more complete rectosigmoid resection resulting in a lower rate of recurrence. Ram et al. acknowledge in their introduction that "to excise a larger amount of prolapsed rectal tissue" is the goal of their "novel technique." However, PSPR does not allow for proper exposure and complete dissection of the rectum which ultimately is counterproductive to performance of a recurrence-free PR or Altemeier Procedure. Tschuor et al. [12] essentially agree with this conclusion 
and note that their $44 \%$ recurrence rate with PSPR is "higher for the PSP resection (PSPR) than for the other perineal procedures the reason must be... the technique itself." The group that originated PSPR, Scherer et al. [11] admit that "The length of resected large bowel by conventional Altemeier is probably greater than with the PSP because the opening of the peritoneal sac eases pulling down the sigmoid and descending colon" resulting in "the resection of a shorter segment of bowel" when performing PSPR explaining the very high and rapid recurrence of rectal prolapse. Furthermore, PSPR does not allow access for levatorplasty which defines the Altemeier Procedure and separates it from mere amputation of the rectum (PR). Some authors note that levatorplasty is easily performed during PR and results in low rates of recurrence with a beneficial effect on postoperative fecal continence [9, 13].

It should be emphasized that Ram et al. [10] ultimately chose the Altemeier Procedure to salvage their 4 patients with rapid recurrence of rectal prolapse following PSPR (29\% recurrence rate). This should prompt the obvious question - why not recommend the Altemeier Procedure as an initial operation rather than this "novel technique" (PSPR) which comes at a much higher cost per operation ("1,600 US Dollars" according to Ram et al. [10], “\$1,850 (US)" according to Scherer et al. [11]) with no discernable improvement in morbidity, mortality or hospital length of stay? Moreover, given the recent low rates of recurrent rectal prolapse combined with the low morbidity/mortality and total avoidance of sexual dysfunction in men versus abdominal operations for rectal prolapse, why not recommend the Altemeier Procedure for all patients, regardless of age $[6,9]$ ?

Conflict of interest None.

\section{References}

1. Auffret M (1882) Un cas de procidence du gros intestine d'une longueur de 90 centimetres: operation par excision: double range de suture; mort. Prog Med 10:650-652

2. Mikulicz J (1889) Zur operative behandlung des prolapses recti et coli invaginati. Arch Klin Chir Berl 38:74-97

3. Miles WE (1933) Recto-sigmoidectomy as a method of treatment for procidentia recti. Proc R Soc Med 26:1445-1448

4. Hughes ES (1949) Discussion on prolapse of the rectum. Proc R Soc Med 41:1007-1011

5. Porter N (1962) Collective results of operations for rectal prolapse. Proc R Soc Med 55:1087-1091

6. Glasgow SC, Birnbaum EH, Kodner IJ, Fleshman JW Jr, Dietz DW (2008) Recurrence and quality of life following perineal proctectomy for rectal prolapse. J Gastrointest Surg 12:1446-1451

7. Altomare DF, Binda G, Ganio E, De Nardi P, Giamundo P, Pescatori M (2009) Long-term outcome of Altemeier's procedure for rectal prolapse. Dis Colon Rectum 52:698-703

8. Kim M, Reibetanz J, Boenicke L, Germer CT, Jayne D, Isbert C (2010) Quality of life after transperineal rectosigmoidectomy. $\mathrm{Br}$ J Surg 97:269-272

9. Cirocco WC (2010) The Altemeier Procedure for rectal prolapse: an operation for all ages. Dis Colon Rectum 53:1618-1623

10. Ram E, Krissi H, Zbar A, Atar E, Joubran S, Rath-Wolfson L (2014) Perineal stapled prolapse resection (PSPR) in elderly patients for external rectal prolapse: early experience. Tech Coloproctol. doi:10.1007/s10151-014-1137-9

11. Scherer R, Marti L, Hetzer FH (2008) Perineal stapled prolapse resection: a new procedure for external rectal prolapse. Dis Colon Rectum 51:1727-1730

12. Tschuor C, Limani P, Nocito A, Dindo D, Clavien P-A, Hahnloser D (2013) Perineal stapled prolapse resection for external rectal prolapse: is it worthwhile in the long-term? Tech Coloproctol 17:537-540

13. Chun SW, Pikarsky AJ, You SY et al (2004) Perineal rectosigmoidectomy for rectal prolapse: role of levatorplasty. Tech Coloproctol 8:3-9 